Адрес статьи / To link this article: http://cat.itmo.ru/ru/2021/v6-i2/277

\title{
Конференция «Интернет и современное общество» в новых условиях
}

\author{
Д.Е. Прокудин ${ }^{1,2}$, А.В. Чугунов ${ }^{1}$ \\ ${ }^{1}$ Университет ИТМО, Россия \\ ${ }^{2}$ Санкт-Петербургский государственный университет, Россия \\ hogben.young@gmail.com, chugunov@egov-center.ru
}

\begin{abstract}
Аннотация. В 2020 году в Санкт-Петербурге традиционно прошла Неделя технологий информационного общества. Базовым мероприятием Недели является Международная объединённая конференция «Интернет и современное общество», которая состоялась уже в двадцать третий раз. В условиях непростой эпидемиологической обстановки она проводилась в онлайн формате с применением информационно-коммуникационных технологий. Конференция, как и все мероприятия Недели технологий информационного общества, прошла на высоком научном уровне. По итогам выступлений участников изданы сборники статей и тезисов, как на русском, так и на английском языках. Сборник статей на английском языке проиндексирован в реферативной наукометрической базе Scopus.
\end{abstract}

Ключевые слова: конференция, Интернет и современное общество, Неделя технологий информационного общества, Санкт-Петербург

С 2016 г. в Санкт-Петербурге проводится Неделя технологий информационного общества, которая объединяет ряд научных и специализированных мероприятий. Базовым научным мероприятием Недели является Международная объединённая конференция «Интернет и современное общество» (Internet and Modern Society - IMS), которая имеет богатую историю и проводится в Санкт-Петербурге ежегодно с 1998 года. Организаторами конференции вот уже на протяжении последних пяти лет являются Университет ИТМО и Некоммерческое партнерство ПРИОР Северо-Запад (https://prior.nw.ru).

Конференция является «объединенной» в связи с тем, что её научная программа объединяет серию специализированных международных и российских научных конференций, симпозиумов, семинаров, круглых столов и других мероприятий, посвященных специальным вопросам развития технологий информационного общества. Отдельные специализированные и проблемно-ориентированные мероприятия проводятся в сотрудничестве $\mathrm{c}$ партнерскими организациями.

В 2020 году была проведена очередная XXIII конференция. В связи с ограничениями, вызванными коронавирусной инфекцией, мероприятия конференции «Интернет и современное общество», как и вся Неделя технологий информационного общества, проводились в онлайнформате (ZOOM) с предварительным размещением всех презентаций и текстов статей в системе, доступной через личные кабинеты участников конференций и предоставляющей возможности сформулировать вопросы докладчикам. Основная логика строилась на том, чтобы дать 
возможность участникам ознакомиться с докладами и презентациями для более продуктивной дискуссии и обсуждения в новом для всех формате, связанном с рисками технического плана, например, неустойчивая связь или помехи при выступлении.

Отбор докладов на конференции и текстов для публикации производится по результатам слепого рецензирования членами программного комитета с использованием международной системы сопровождения научных конференций Easychair.org. При этом для оперативной и независимой подготовки конференции были созданы отдельные контейнеры для всех мероприятий объединённой конференции.

В рамках Недели технологий информационного общества Санкт-Петербурге в 2020 г. были проведены следующие основные мероприятия.

Симпозиум молодых ученых «Цифровые трансформации: перспективные социальноэкономические и гуманитарные исследования». Он открывал научную программу Недели 17 июня 2020 г. Организаторами Симпозиума были Университет ИТМО и Северо-Западный институт управления РАНХиГС. Основная миссия Симпозиума - способствовать формированию в России сообщества молодых специалистов, ведущих исследования и разработки в области технологий информационного общества, цифровых трансформаций в различных сферах. На молодежном симпозиуме были представлены доклады, отражающие перспективные разработки, а также практические результаты научных исследований.

Основные секции объединенной конференции «Интернет и современное общество» были проведены 18-20 июня 2020 г. К ним традиционно относятся:

- Информационные системы для науки и образования. Доклады, заслушанные на этой секции, были посвящены результатам исследований как по разработке различных информационных систем и программного обеспечения, так и применению различных информационно-коммуникационных технологий в научной сфере и образовании.

- Электронное обучение и дистанционные образовательные технологии. Участники, выступавшие на этой секции, рассматривали различные аспекты и проблемы разработки, внедрения и использования информационно-коммуникационных технологий в образовательной среде.

- Культурология киберпространства. В сферу исследований участников данной секции входит кросс-культурный анализ проблем влияния технологий информационного пространства на различные общественные формации, в том числе на формирование социокультурного облика поколения $Z$.

В программе объединенной конференции в 2020 году были проведены специализированные международные семинары, которые включали две сессии - на русском и английском языках:

- 19 июня состоялся Международный семинар «Киберпсихология» (Internet Psychology IntPsy-2020);

- 19-20 июня был проведён Международный семинар «Электронное управление» (E-Governance-2020);

- 20 июня прошёл Международный семинар «Компьютерная лингвистика» (Computational Linguistics - CompLing-2020).

В рамках Недели технологий информационного общества вот уже в четвёртый раз прошла Международная конференция «Digital Transformation \& Global Society» (DTGS-2020), рабочим языком которой является английский. Её организаторами являются Университет ИТМО и НИУ ВШЭ, Санкт-Петербург (сайт конференции: http://dtgs-conference.org).

По результатам проведения объединенной конференции IMS-2020 было издано три сборника научных трудов, которые с 2017 года издаются как сериальные издания, сборник тезисов на русском языке, а также сборник статей на английском языке:

- Информационное общество: образование, наука, культура и технологии будущего (ISSN 2587-8557), вып. 4 [1];

- Государство и граждане в электронной среде (ISSN 2541-979X), вып. 4 [3];

- Компьютерная лингвистика и вычислительные онтологии (ISSN 2541-9781), вып. 4 [2];

- Интернет и современное общество: сборник тезисов докладов IMS-2020 [4].

International Culture \& Technology Studies, Vol. 6, No. 2 
Электронные версии сборников конференции размещены в свободном доступе по лицензии Creative Commons CC-BY 3.0 Unported (http://creativecommons.org/licenses/by/3.0/deed.ru) на сайте материалов конференции «Интернет и современное общество» (http://ojs.itmo.ru). C 2017 года всем статьям присваивается международный идентификатор DOI, а информация на уровне метаданных размещается в информационной системе CrossRef (https://search.crossref.org). Тексты статей и тезисов также доступны в формате PDF в открытом репозитории Университета ИТМО (https://openbooks.itmo.ru/ru/collections/). Метаданные сборников размещаются в Научной электронной библиотеке (https://elibrary.ru), а все статьи и тезисы индексируются в Российском индексе научного цитирования (РИНЦ).

Статьи, представленные для докладов на английском языке и прошедшие рецензирование международным программным комитетом, опубликованы в сборнике «IMS2020 Proceedings», который издан в CEUR-WS (Free Open-Access Proceedings for Scientific Conferences and Workshops) на английском языке [5]. Статьи этого сборника проиндексированы в реферативной базе научных публикаций Scopus.

После проведения конференции оргкомитетом была проведена работа по подготовке метаданных сборников статей конференции с 2017 года для подачи заявки на размещение их в одной из самых авторитетных библиографических баз данных по информатике и информационным технологиям DBLP. Эта база создана в Университете Трира (Германия). В 2021 году сборники статей конференции «Интернет и современное общество» были проиндексированы в этой базе (https://dblp.dagstuhl.de/db/conf/ims2/index.html).

Организационный комитет конференции «Интернет и современное общество» традиционно сотрудничает с научными и научно-популярными журналами. В том числе, с 2017 года осуществляется тесное сотрудничество с научным журналом «International Journal of Open Information Technologies». Каждый год результатом этого сотрудничества является специальный номер журнала, в котором публикуются статьи, подготовленные авторами по итогам их докладов и отмеченные оргкомитетом конференции $[6,7,8]$. После проведения конференции в 2020 году также был подготовлен специальный номер журнала «International Journal of Open Information Technologies» [9], содержащий статьи, которые были подготовлены по итогам сделанных докладов на конференции «Интернет и современное общество» (IMS-2020) и отмечены её организаторами. Помимо этого, в номер включены статьи на русском языке участников международной конференции «Digital Transformation \& Global Society» (DTGS-2020), подготовленные по итогам их выступлений на английском языке. Используя такой подход, организаторы Недели технологий информационного общества в Санкт-Петербурге стремятся распространять среди русскоязычной научной общественности актуальные результаты научных исследований, обнародованные на международном уровне.

В целом необходимо отметить как высокий уровень научной программы конференции «Интернет и современное общество» (IMS-2020), так и организации самой конференции, которая прошла в новых специфических условиях.

\section{Литература}

[1] Информационное общество: образование, наука, культура и технологии будущего. Выпуск 4 (Труды XXIII Международной объединенной научной конференции «Интернет и современное общество», IMS2020 (сборник научных статей). - СПб: Университет ИТМО, 2020. 160 с. DOI: 10.17586/2587-85572020-4.

[2] Компьютерная лингвистика и вычислительные онтологии. Выпуск 4 (Труды XXIII Международной объединенной научной конференции «Интернет и современное общество», IMS-2020, Санкт-Петербург, $17-20$ июня 2020 г. Сборник научных статей). - СПб: Университет ИТМО, 2020. 132 с. DOI: $10.17586 / 2541-9781-2020-4$

[3] Государство и граждане в электронной среде. Выпуск 4 (Труды XXIII Международной объединенной научной конференции «Интернет и современное общество», IMS-2020, Санкт-Петербург, $17-20$ июня 2020 г. Сборник научных трудов). - СПб: Университет ИТМO, 2020. 126 c. DOI: 10.17586/2541-979X2020-4.

[4] Интернет и современное общество: сборник тезисов докладов [Электронный ресурс] / Труды XXIII Международной объединенной научной конференции «Интернет и современное общество» (IMS-2020),

Культура и технологии, Том 6, № 2 
Санкт-Петербург, 17 - 20 июня 2020 г. СПб: Университет ИТМО, 2020. 34 с. URL: http://ojs.itmo.ru/index.php/IMS/issue/view/57.

[5] CEUR Workshop Proceedings. 2021. Vol. 2813 / Proceedings of the International Conference "Internet and Modern Society" (IMS-2020), St. Petersburg, Russia, 17-20 June 2020. Radomir V. Bolgov, Andrei V. Chugunov, Alexander E. Voiskounsky (eds.). URL: http://ceur-ws.org/Vol-2813.

[6] International Journal of Open Information Technologies. 2017. Toм 5, № 11. URL: http://injoit.org/index.php/j1/issue/view/60.

[7] International Journal of Open Information Technologies. 2018. Toм 6, № $12 . \quad$ URL: http://injoit.org/index.php/j1/issue/view/73.

[8] International Journal of Open Information Technologies. 2020. Toм 8, № $1 . \quad$ URL: http://injoit.org/index.php/j1/issue/view/86.

[9] International Journal of Open Information Technologies. 2020. Toм 8 , № $11 . \quad$ URL: http://injoit.org/index.php/j1/issue/view/97

\title{
Conference "Internet and Modern Society" in new situation
}

\author{
D.E. Prokudin ${ }^{1,2}$, A.V. Chugunov ${ }^{1}$ \\ ${ }^{1}$ University ITMO, Russia \\ ${ }^{2}$ Saint-Petersburg State University, Russia
}

\begin{abstract}
In 2020, the Information Society Technology Week was traditionally held in St. Petersburg. The main event of the Week is the International Joint Conference "The Internet and Modern Society", which was held for the twenty-third time. In the stipulations of Russian epidemiological situation, it was held in an online format with the use of information and communication technologies. The conference, like all events of the Information Society Technology Week, was held at a high scientific level. Following the results of the participants ' speeches, collections of articles and abstracts were published, both in Russian and in English. The collection of articles in English is indexed in the Scopus abstract scientometric database.
\end{abstract}

Keywords: conference, Internet and Modern Society, Information Society Technology Week, St. Petersburg

\section{References}

[1] Informatsionnoe obshchestvo: obrazovanie, nauka, kul'tura i tekhnologii budushchego. Vypusk 4 (Trudy XXIII Mezhdunarodnoy ob"edinennoy nauchnoy konferentsii «Internet i sovremennoe obshchestvo», IMS-2020 (sbornik nauchnykh statey). — SPb: Universitet ITMO, 2020. 160 s. DOI: 10.17586/2587-8557-2020-4.

[2] Komp'yuternaya lingvistika i vychislitel'nye ontologii. Vypusk 4 (Trudy XXIII Mezhdunarodnoy ob"edinennoy nauchnoy konferentsii «Internet i sovremennoe obshchestvo», IMS-2020, Sankt-Peterburg, 17 - 20 iyunya 2020 g. Sbornik nauchnykh statey). — SPb: Universitet ITMO, 2020. 132 s. DOI: 10.17586/2541-9781-2020-4

[3] Gosudarstvo i grazhdane v elektronnoy srede. Vypusk 4 (Trudy XXIII Mezhdunarodnoy ob"edinennoy nauchnoy konferentsii «Internet i sovremennoe obshchestvo», IMS-2020, Sankt-Peterburg, 17 - 20 iyunya 2020 g. Sbornik nauchnykh trudov). - SPb: Universitet ITMO, 2020. 126 s. DOI: 10.17586/2541-979X-2020-4.

[4] Internet i sovremennoe obshchestvo: sbornik tezisov dokladov [Elektronnyy resurs] / Trudy XXIII Mezhdunarodnoy ob"edinennoy nauchnoy konferentsii «Internet i sovremennoe obshchestvo» (IMS-2020), Sankt-Peterburg, $17-20$ iyunya 2020 g. $\quad$ SPb: Universitet ITMO, $2020 . \quad 34$ s. URL: http://ojs.itmo.ru/index.php/IMS/issue/view/57.

[5] CEUR Workshop Proceedings. 2021. Vol. 2813 / Proceedings of the International Conference "Internet and Modern Society" (IMS-2020), St. Petersburg, Russia, 17-20 June 2020. Radomir V. Bolgov, Andrei V. Chugunov, Alexander E. Voiskounsky (eds.). URL: http://ceur-ws.org/Vol-2813.

[6] International Journal of Open Information Technologies. 2017. Toм 5, № 11. URL: http://injoit.org/index.php/j1/issue/view/60.

[7] International Journal of Open Information Technologies. 2018. Toм 6, № $12 . \quad$ URL: http://injoit.org/index.php/j1/issue/view/73.

[8] International Journal of Open Information Technologies. 2020. Toм $8, \quad$ № $1 . \quad$ URL: http://injoit.org/index.php/j1/issue/view/86.

[9] International Journal of Open Information Technologies. 2020. Toм 8, № $11 . \quad$ URL: http://injoit.org/index.php/j1/issue/view/97

International Culture \& Technology Studies, Vol. 6, No. 2 